\title{
European Prospective Investigation into Cancer and Nutrition (EPIC): study populations and data collection
}

\author{
E Riboli ${ }^{1}, *, \mathrm{KJ} \mathrm{Hunt}^{2}$, N Slimani ${ }^{1}$, P Ferrari ${ }^{1}, \mathrm{~T} \mathrm{Norat}^{1}$, M Fahey ${ }^{1}$, UR Charrondière ${ }^{1}$, \\ B Hémon ' ${ }^{1}, C^{2}$ Casagrande ${ }^{1}$, J Vignat ${ }^{1}$, K Overvad ${ }^{3}$, A Tiønneland ${ }^{4}$, F Clavel-Chapelon ${ }^{5}$,

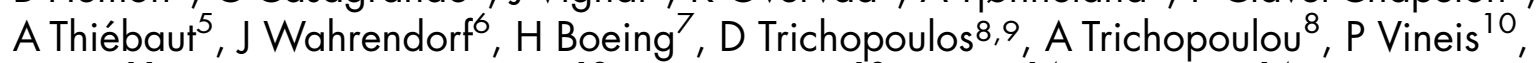 \\ D Palli ${ }^{11}$, HB Bueno-de-Mesquita ${ }^{12}$, PHM Peeters ${ }^{13}$, E Lund $^{14}$, D Engeset $^{14}$,

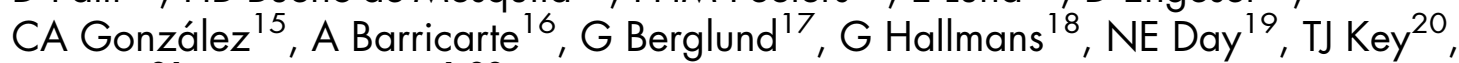
R Kaaks $^{21}$ and R Saracci ${ }^{1,22}$

${ }^{1}$ Unit of Nutrition and Cancer, International Agency for Research on Cancer (IARC-WHO), 150 cours AlbertThomas, 69372 Lyon Cedex 08, France: ${ }^{2}$ Division of Clinical Epidemiology, University of Texas Health Science Center, San Antonio, TX, USA: ${ }^{3}$ Department of Epidemiology and Social Medicine, University of Aarhus, Denmark: ${ }^{4}$ Institute of Cancer Epidemiology, Danish Cancer Society, Copenhagen, Denmark: ${ }^{5}$ INSERM, U52 1, Institute Gustave Roussy, Villejuif, France: ${ }^{6}$ German Cancer Research Centre, Heidelberg, Germany: ${ }^{7}$ Department of Epidemiology, German Institute of Human Nutrition, Potsdam-Rehbrücke, Germany: ${ }^{8}$ Department of Hygiene and Epidemiology, School of Medicine, University of Athens, Greece: ${ }^{9}$ Department of Epidemiology, Harvard School of Public Health, Boston, MA, USA: ${ }^{10}$ Department of Biomedical Sciences and Human Oncology, University of Turin, Italy: ${ }^{11}$ Molecular \& Nutrition Epidemiology Unit, CSPO, Scientific Institute of Tuscany, Florence, Italy: ${ }^{2}$ Department of Epidemiology, National Institute of Public Health and the Environment, Bilthoven, The Netherlands: ${ }^{13}$ Julius Center for General Practice and Patient Oriented Research, University of Utrecht, The Netherlands: ${ }^{14}$ Institute of Community Medicine, University of Tromsø, Norway: ${ }^{15}$ Department of Epidemiology, Catalan Institute of Oncology, Barcelona, Spain: ${ }^{16}$ Service of Surveillance and Epidemiological Control, Institute of Public Health of Navarra, Pamplona, Spain: ${ }^{17}$ Department of Medicine, Lund University, Malmö University Hospital, Sweden: ${ }^{18}$ Public Health and Clinical Medicine, University Hospital of Northern Sweden, Umeå, Sweden: ${ }^{19}$ Department of Public Health and Primary Care, School of Clinical Medicine, University of Cambridge, UK: ${ }^{20}$ Cancer Research UK, Epidemiology Unit, University of Oxford, UK: ${ }^{21}$ Hormones and Cancer Group, IARC-WHO, Lyon, France: ${ }^{22}$ Division of Epidemiology, IFC National Research Council, Pisa, Italy

\begin{abstract}
The European Prospective Investigation into Cancer and Nutrition (EPIC) is an ongoing multi-centre prospective cohort study designed to investigate the relationship between nutrition and cancer, with the potential for studying other diseases as well. The study currently includes 519978 participants (366521 women and 153457 men, mostly aged 35-70 years) in 23 centres located in 10 European countries, to be followed for cancer incidence and cause-specific mortality for several decades. At enrolment, which took place between 1992 and 2000 at each of the different centres, information was collected through a non-dietary questionnaire on lifestyle variables and through a dietary questionnaire addressing usual diet. Anthropometric measurements were performed and blood samples taken, from which plasma, serum, red cells and buffy coat fractions were separated and aliquoted for long-term storage, mostly in liquid nitrogen. To calibrate dietary measurements, a standardised, computer-assisted 24-hour dietary recall was implemented at each centre on stratified random samples of the participants, for a total of 36900 subjects. EPIC represents the largest single resource available today world-wide for prospective investigations on the aetiology of cancers (and other diseases) that can integrate questionnaire data on lifestyle and diet, biomarkers of diet and of endogenous metabolism (e.g. hormones and growth factors) and genetic polymorphisms. First results of case-control studies nested within the cohort are expected early in 2003. The present paper provides a description of the EPIC study, with the aim of simplifying reference to it in future papers reporting substantive or methodological studies carried out in the EPIC cohort.
\end{abstract}

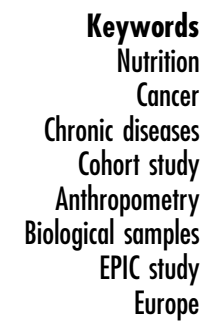

Keywords Cancer ic diseases Cohort study Anthropometry EPIC study Europe 
The existence of a relationship between nutrition and cancer was first shown clearly in the 1940s in a series of experimental studies in which severe energy restriction markedly reduced the occurrence of cancers in mice ${ }^{1}$. In the 1960s, following the development of cancer registries, ecological studies drew attention to the large world-wide variations in cancer incidence, and provided first suggestions that these variations might be related to differences in lifestyle, particularly diet ${ }^{2-4}$. In the 1970 s and 1980s, a large number of traditional case-control studies were conducted to identify dietary risk factors with greater specificity, and since the late 1980s these studies have been followed by a series of prospective cohort studies 5 .

In spite of several decades of research, comparatively few nutrition-related factors have been established unequivocally as playing a causal role in human cancer occurrence. These established factors include obesity and alcohol consumption ${ }^{5}$. In fact, epidemiological studies on nutrition and cancer have faced several methodological problems. Dietary habits are difficult to assess accurately and dietary exposures relevant to the aetiology of today's cancer incidence or mortality may have occurred over many years. Food patterns and specific food components, macro- and micronutrients, may all play aetiological roles and their effects may also be modified by other lifestyle factors such as physical activity or childbearing patterns. Case-control studies may be flawed by differential bias between cases and controls in the recall of dietary habits, and case-control studies that use biomarkers of diet or metabolism may also be flawed because the markers may be altered by the presence or diagnosis of a tumour. In principle, prospective cohort studies are not subject to these two major forms of bias. But, unless they are very large in size, they are inadequate to generate informative data on the aetiology of less common forms of cancer, such as those of the oesophagus, gall bladder, thyroid gland, ovary or endometrium. Even for the common forms of cancer, such as those of the lung, colon-rectum, breast, prostate and stomach, prospective cohort studies may prove less than adequate as soon as the aetiological investigation focuses on sub-types characterised by localisation, histology or other biological traits.

Finally, a drawback of prospective studies has been the fact that so far they have often been conducted within populations with relatively homogeneous lifestyles and dietary patterns. This homogeneity, combined with relatively large errors in dietary intake assessments, may make it very difficult to demonstrate moderate associations of specific aspects of diet with cancer risk.

In an attempt to overcome these various limitations, the International Agency for Research on Cancer (IARC) initiated the European Prospective Investigation into Cancer and Nutrition (EPIC) - a multi-centre prospective cohort study in Western Europe ${ }^{6-10}$. The study has been supported from its beginning by the Europe Against
Cancer programme of the European Union. Initiated in 1992, this study has grown progressively into a collaborative endeavour between 23 centres in 10 European countries. The principal aim of EPIC is to investigate, in a prospective manner, the aetiology of cancers at various sites (as well as other forms of chronic disease) in relation to diet and lifestyle, taking advantage both of the contrast in cancer rates and dietary habits between centres and countries and of the large overall size of the study, which makes it possible to explore interactions between nutritional, genetic, hormonal and lifestyle factors.

Enrolment of the EPIC cohort participants and collection of baseline questionnaire data, anthropometric measurements and blood samples have now been completed for all countries. By May 2002, the follow-up for cancer incidence had already led to the identification of large numbers (1000-4500 cases) of subjects who developed cancer after cohort enrolment at one of the major sites (lung, colon-rectum, prostate and breast). This represents a total of about 16000 incident cases. In previous reports, the rationale for the EPIC study and its future perspectives have been discussed ${ }^{6,9,10}$. In the present paper, we describe in some detail the individual EPIC study cohorts and their source populations, as well as the baseline information and biological samples collected from the participants of each cohort.

\section{Methods}

\section{Outline}

EPIC is an ongoing multi-centre prospective cohort study. The prospective cohort approach includes the collection of baseline questionnaire and interview data on diet and non-dietary variables, as well as anthropometric measurements and blood samples for long-term storage from apparently healthy populations. The cohort participants are followed over time for the occurrence of cancer and other diseases, as well as for overall mortality, to allow incidence and mortality comparisons by exposure variables. At regular intervals, follow-up questionnaires are used to update information on selected aspects of lifestyle that are known or strongly suspected to be related to cancer risk and that may have changed over time. The EPIC study has recruited 519978 participants, in 23 centres located in 10 European countries. The study started with 17 research centres in seven core EPIC countries (France, Germany, Greece, Italy, The Netherlands, Spain and the UK). Subsequently, these were joined by centres in three Scandinavian countries (Sweden, Denmark and Norway) and one centre in Italy (Naples) that were conducting broadly similar prospective studies. The enrolment of subjects included in all EPIC centres took place between 1992 and 2000. 


\section{Source populations, invitation and study logistics}

Participant eligibility within each cohort was based essentially on geographic or administrative boundaries. The source populations were identified according to age, gender and, optionally, other criteria (Table 1$)^{11-17}$. The age range was generally from 35 to 70 years (Table 1 ). The actual study populations are samples of convenience of volunteers agreeing to participate, but not required to be random samples of defined populations; moreover, only some of the centres have maintained records of all the individuals invited to participate. As shown in Table 1, in the majority of study centres, subjects were invited from the general adult population residing in a given town or geographical area. There were, however, exceptions to this recruitment scheme. The French cohort was based on members of the health insurance for teachers (with the aim of facilitating follow-up for incidence of cancer and other diseases); components of the Italian and Spanish cohorts included members of local blood donor associations; the cohorts in Utrecht (The Netherlands) and Florence (Italy) included women invited for a local population-based breast cancer screening programme. In Oxford (UK) half of the cohort was recruited among subjects who did not eat meat, including vegans (who consume no animal products), lacto-ovo vegetarians and fish eaters (i.e. consumers of fish but not meat). In France, Norway, Utrecht (The Netherlands) and Naples (Italy) only women were recruited.

Centre-specific information on geographical/political area, source population, eligibility criteria and enumeration of invited participants are shown in Table 1, while Table 2 provides centre- and gender-specific information on study population size, enrolment dates and participant age at enrolment.

As a rule, participants were invited to participate either by mail or in person (Table 1). Individuals who agreed to participate signed an informed consent agreement and were mailed a questionnaire on diet and a questionnaire on lifestyle. Most participants completed these questionnaires at home and were then invited to a study centre for an examination. This included collection of the two completed questionnaires, venepuncture, anthropometry and measurement of blood pressure. For the blood pressure measurements, uniform procedures were recommended but no standard method or common type of instrument was introduced ${ }^{18}$. Among the seven initial EPIC countries, the centres in Italy (except Ragusa), the UK (except Oxford), The Netherlands and Germany followed these procedures. In France, a study that started in 1990 included lifestyle questions with self-reported anthropometry measurements; the participants enrolled in EPIC are those who answered the dietary questionnaire. A subset of the French cohort (20 725 women close to a metropolitan area) later came to a field centre, donated a blood sample, and underwent blood pressure and anthropometry measurements. In Spain and Ragusa (Italy), the recruited participants received the non-dietary questionnaire by mail, and were invited to a study centre for an examination that included collection of the lifestyle questionnaire, venepuncture, anthropometry and blood pressure measurements (in Spain only in sub-sample of the cohort), as well as an interviewer-administered computer-driven dietary questionnaire. Finally, in Greece, participants were initially invited by mail, sent a questionnaire, and asked to come for an examination at a study centre; however, recruitment numbers were so low that active recruitment was initiated. In contrast to most other EPIC centres, actively recruited Greek participants had their EPIC study centre examination at enrolment and all completed an interviewer-administered questionnaire on diet and a questionnaire on lifestyle. In Denmark and Malmö (Sweden), the participants filled in dietary questionnaires at home and lifestyle questionnaires at the study centres. In Umeå (Sweden), both questionnaires were completed at the study centre. In Norway, participants completed an initial mailed questionnaire unrelated to EPIC, completed a subsequent mailed questionnaire for EPIC, and then had blood samples mailed to the study centre in Troms $\varnothing$ for processing.

\section{Dietary intake assessments}

Dietary intake was assessed by a number of different instruments that had been developed and validated previously in a series of studies within the various source populations participating in EPIC (Table 3$)^{19-23}$. Following the results of the methodological studies and taking into account the local context, three dietary assessment methods were adopted:

1. Extensive self-administrated quantitative dietary questionnaires, containing up to 260 food items and estimating individual average portions systematically, were used in northern Italy, The Netherlands, Germany and Greece (where dietary questionnaires were interviewer-administered). Questionnaires, similar in content to the self-administered quantitative dietary questionnaires but structured by meals, were used in Spain, France and Ragusa (south Italy). To increase compliance, the centres in Spain and Ragusa performed a face-to-face dietary interview using a computerised dietary program, whereas the dietary questionnaire was self-reported in France.

2. Semi-quantitative food-frequency questionnaires (with the same standard portion(s) assigned to all subjects) were used in Denmark, Norway, Naples in Italy and Umeå in Sweden.

3. Combined dietary methods were used in the UK and Malmö (Sweden). The two British centres used both a semi-quantitative food-frequency questionnaire and a 7-day record, whereas a method combining a short non-quantitative food-frequency questionnaire with a 14-day record on hot meals (lunches and dinners) was developed in Malmö. 


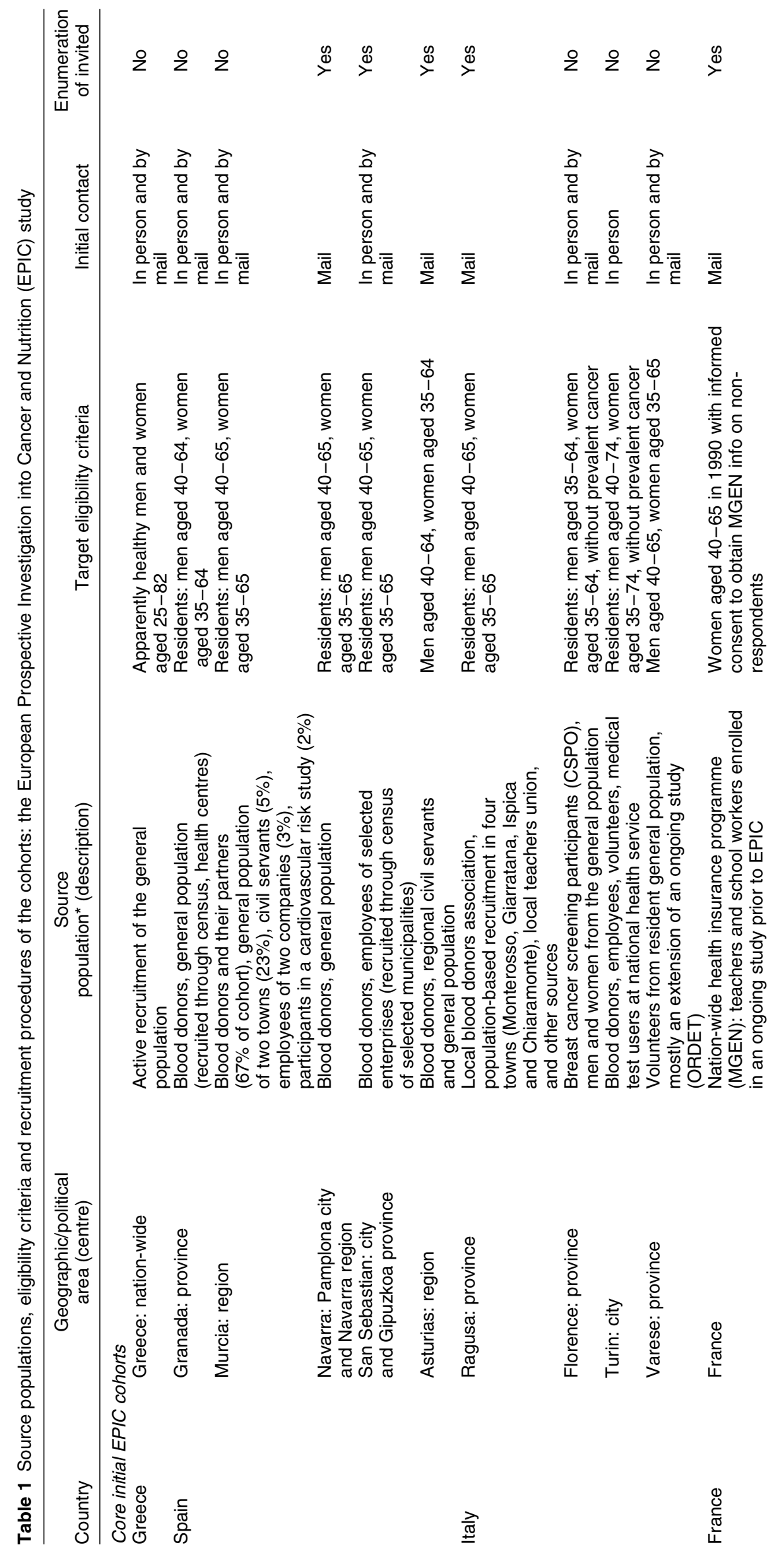




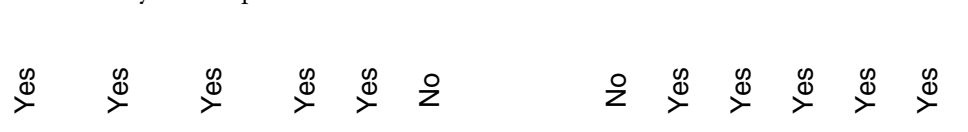

$\overline{\overline{\bar{\pi}}} \quad \overline{\overline{\bar{\pi}}} \quad \overline{\overline{\bar{\omega}}} \quad \overline{\overline{\bar{\pi}}} \overline{\overline{\bar{\pi}}} \overline{\overline{\bar{\pi}}}$
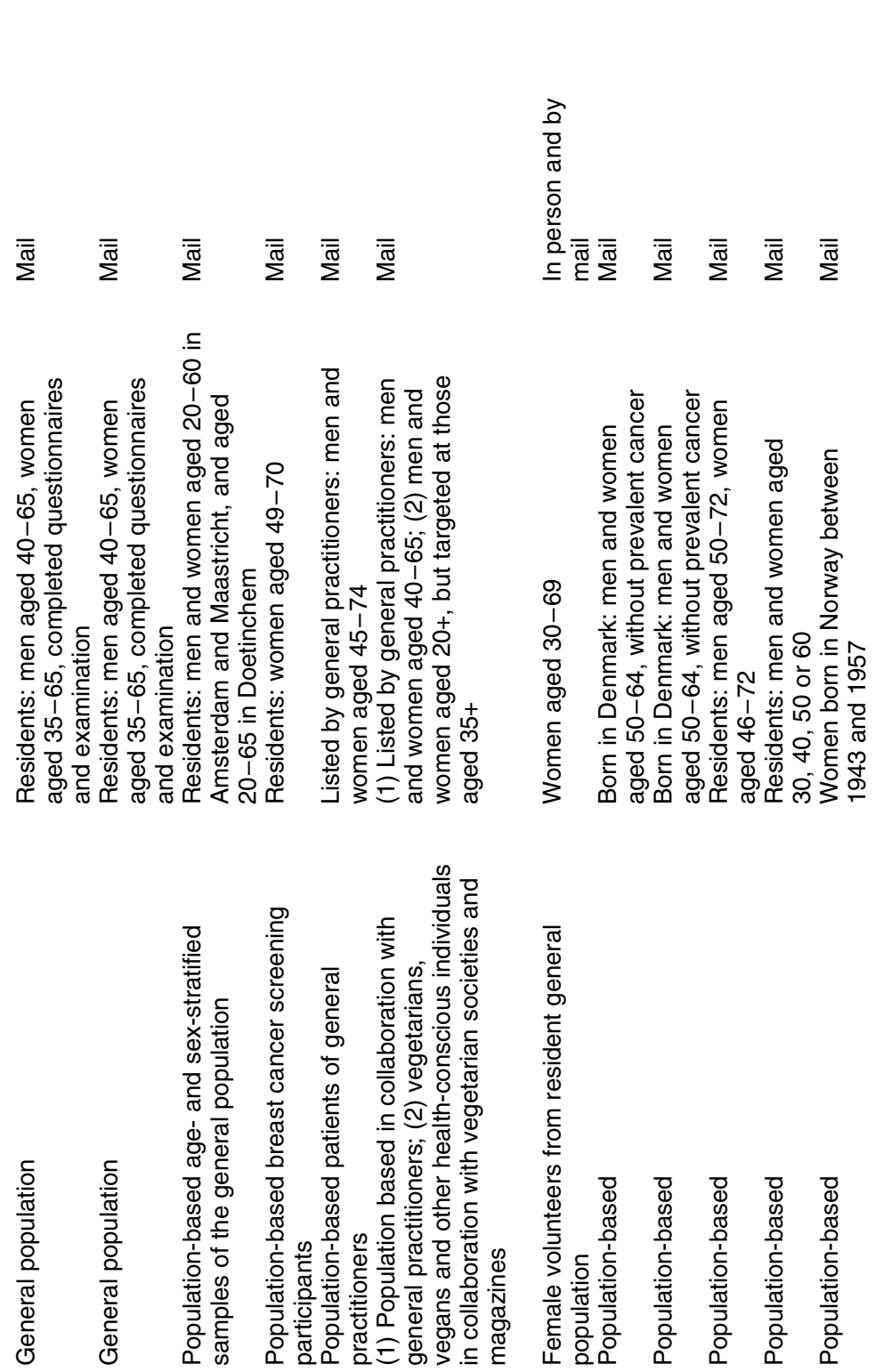

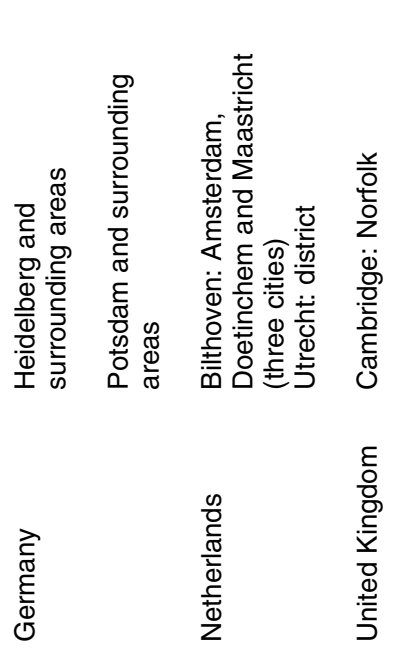

Table 2 Characteristics of the cohorts: the European Prospective Investigation into Cancer and Nutrition (EPIC) study

\begin{tabular}{|c|c|c|c|c|c|}
\hline Country & Centre & & $n^{*}$ & $\begin{array}{c}\text { Enrolment } \\
\text { period (date) }\end{array}$ & $\begin{array}{l}\text { Enrolment age (years) } \\
\text { (1st-99th percentile) }\end{array}$ \\
\hline \multicolumn{6}{|c|}{ Core initial EPIC cohorts } \\
\hline \multirow{2}{*}{\multicolumn{2}{|c|}{ Greece }} & Male & 11954 & $1994-1999$ & $30-76$ \\
\hline & & Female & 16618 & $1994-1999$ & $30-76$ \\
\hline \multirow[t]{10}{*}{ Spain } & Granada & Male & 1796 & $1992-1996$ & $35-65$ \\
\hline & & Female & 6083 & $1992-1996$ & $35-65$ \\
\hline & Murcia & Male & 2685 & $1992-1996$ & $38-65$ \\
\hline & & Female & 5831 & $1992-1996$ & $35-65$ \\
\hline & Navarra & Male & 3908 & $1992-1995$ & $40-64$ \\
\hline & & Female & 4176 & $1992-1995$ & $35-64$ \\
\hline & San Sebastian & Male & 4158 & 1992-1995 & $40-65$ \\
\hline & & Female & 4259 & $1992-1995$ & $35-65$ \\
\hline & Asturias & Male & 3085 & $1992-1995$ & $40-65$ \\
\hline & & Female & 5459 & $1992-1995$ & $35-65$ \\
\hline \multirow[t]{8}{*}{ Italy } & Ragusa & Male & 3053 & $1993-1997$ & $37-65$ \\
\hline & & Female & 3350 & $1993-1997$ & $35-65$ \\
\hline & Florence & Male & 3514 & $1993-1998$ & $35-65$ \\
\hline & & Female & 10083 & $1992-1998$ & $35-65$ \\
\hline & Turin & Male & 6047 & $1993-1998$ & $35-65$ \\
\hline & & Female & 4557 & $1993-1998$ & $35-65$ \\
\hline & Varese & Male & 2557 & $1995-1997$ & $40-65$ \\
\hline & & Female & 9526 & $1993-1997$ & $35-72$ \\
\hline France & & Female & 72996 & $1993-1997$ & $43-68$ \\
\hline \multirow[t]{4}{*}{ Germany } & Heidelberg & Male & 11929 & $1994-1998$ & $40-65$ \\
\hline & & Female & 13617 & $1994-1998$ & $35-65$ \\
\hline & Potsdam & Male & 10904 & $1994-1998$ & $38-65$ \\
\hline & & Female & 16644 & $1994-1998$ & $35-65$ \\
\hline \multirow[t]{3}{*}{ Netherlands } & Bilthoven & Male & 10280 & $1993-1997$ & $21-63$ \\
\hline & & Female & 12435 & $1993-1997$ & $21-64$ \\
\hline & Utrecht & Female & 17357 & $1993-1997$ & $49-70$ \\
\hline \multirow[t]{4}{*}{ United Kingdom } & Cambridge & Male & 13698 & $1993-1998$ & $41-76$ \\
\hline & & Female & 16744 & $1993-1998$ & $41-76$ \\
\hline & Oxford & Male & 13214 & $1994-2000$ & $22-83$ \\
\hline & & Female & 44284 & $1993-2000$ & $21-79$ \\
\hline \multicolumn{6}{|c|}{ Associated EPIC cohorts } \\
\hline Italy & Naples & Female & 5062 & $1993-1997$ & $35-68$ \\
\hline \multirow[t]{4}{*}{ Denmark } & Aarhus & Male & 8433 & $1995-1997$ & $50-65$ \\
\hline & & Female & 8721 & $1995-1997$ & $50-65$ \\
\hline & Copenhagen & Male & 18746 & $1993-1997$ & $50-65$ \\
\hline & & Female & 21154 & $1993-1997$ & $50-65$ \\
\hline \multirow[t]{4}{*}{ Sweden } & Malmö & Male & 11063 & $1991-1996$ & $47-72$ \\
\hline & & Female & 17035 & $1991-1996$ & $45-73$ \\
\hline & Umeå & Male & 12433 & $1992-1996$ & $30-60$ \\
\hline & & Female & 13299 & $1992-1996$ & $30-60$ \\
\hline Norway & Troms $\varnothing$ & Female & 37231 & $1998-1998$ & $41-56$ \\
\hline
\end{tabular}

*By April 2002.

The EPIC study aims to increase the overall statistical power of identifying diet-disease relationships by combining study populations that have different types of diets and lifestyles and different cancer incidence rates, resulting in increased overall ranges of dietary exposures and cancer risks. Any global statistical analysis that takes account of the total range of dietary exposures of all sub-cohorts combined requires that the dietary assessments obtained in each of the sub-cohorts be comparable on an absolute scale. Such comparability, however, can be compromised by the use of different dietary assessment methods across the 23 EPIC centres. To overcome this problem, it was decided to collect additional dietary intake data by a computerassisted 24-hour dietary recall (EPIC-SOFT) in representative sub-samples of $5-12 \%$ of study participants in each of the sub-cohorts (about $1.5 \%$ in the British cohorts). In total, 24-hour recalls were collected from 36900 EPIC participants $^{24-26}$. The baseline dietary assessments conducted on all EPIC participants, used locally to estimate long-term usual dietary intake, will be used to rank subjects within centres, while the 24-hour dietary recall can be used as a reference method to correct for systematic between-centre over- or underestimations in the baseline dietary assessments ${ }^{27}$. The calibration study, its rationale and its standardisation are described in detail elsewhere ${ }^{25-31}$. A common food composition database for a number of nutrients, standardised across the European countries involved in EPIC, is currently being developed ${ }^{32,33}$. 
Table 3 Baseline dietary assessment: the European Prospective Investigation into Cancer and Nutrition (EPIC) study

\begin{tabular}{|c|c|c|c|}
\hline Location & Assessment tool(s) and its(their) structure & Administered & $\begin{array}{l}\text { Number } \\
\text { of items }\end{array}$ \\
\hline \multicolumn{4}{|c|}{ Core initial EPIC cohorts } \\
\hline France & Quantitative dietary questionnaire structured by meals $\dagger$ & Self & 210 \\
\hline Northern Italy $\ddagger$ & Quantitative dietary questionnaire structured by meal courses§ & Self & 236 \\
\hline Italy, Ragusa & Quantitative dietary questionnaire structured by meals, computer-driven $†$ & Face-to-face & 266 \\
\hline Spain & Quantitative dietary questionnaire structured by meals, computer-drivent & Face-to-face & 7369 \\
\hline United Kingdom & (1) Semi-quantitative FFQ\|; (2) 7-day records (diaries) & Self & 170 \\
\hline Netherlands & Quantitative dietary questionnaire§ & Self & 213 \\
\hline Greece & Quantitative dietary questionnaire§ & Face-to-face & 2609 \\
\hline Germany & Quantitative dietary questionnaire§ & Self & 254 \\
\hline \multicolumn{4}{|c|}{ Associated EPIC cohorts } \\
\hline Sweden, Malmö & Combination of semi-quantitative FFQ\| and 14-day record of hot meals & Self** & $2443+\dagger$ \\
\hline Sweden, Umeå & Semi-quantitative FFQ\| & Self & 98 \\
\hline Denmark & Semi-quantitative FFQ\| & Self & 173 \\
\hline Norway & Semi-quantitative FFQ\| & Self & 88 \\
\hline Italy, Naples & Semi-quantitative FFQ\| & Face-to-face & 158 \\
\hline
\end{tabular}

$\mathrm{FFQ}$ - food-frequency questionnaire.

* Number of items is defined as the number of foods plus the number of standard mixed recipes.

†Questionnaire structured by main meals (breakfast, lunch, dinner, between-meal food consumption occasions) with meal-specific food frequency and portion.

$\ddagger$ Florence, Turin and Varese.

$\S$ Individual average portion sizes were estimated using series of photographs, standard units and/or household measurements.

I Open-ended sections in the questionnaire.

\| The same standard portion(s) were assigned to all subjects. In Denmark, sex-specific mean portions were used to quantify standard mixed recipes.

** Self-reported during the main examination at the centre, and checked immediately by the interviewer.

†† Essentially open-ended dietary assessment method.

\section{Questionnaire data on non-dietary variables}

Apart from diet, questionnaire data were collected on a large number of lifestyle and health factors that are of interest in studies on nutrition and cancer, as they may be related to nutritional status or may be known or suspected cancer risk factors. For the seven initial EPIC countries, a common set of questions and possible answers was agreed upon and translated into national questionnaires. This included questions on education and socio-economic status; current job, current and past occupation which might have led to exposure to carcinogens; history of previous illness, disorders or surgical operations; lifetime history of tobacco smoking; lifetime history of consumption of alcoholic beverages; physical activity (occupational, walking, cycling, gardening, housework, physical exercise, climbing stairs); menstrual and reproductive history; and use of exogenous hormones for contraception and postmenopausal replacement therapy (Table 4). In Denmark, Sweden and Norway and in the Naples centre in Italy, which joined EPIC at a later stage, questionnaires on non-dietary variables had been developed quite independently of those in the initial EPIC countries. Nevertheless, their questionnaires do cover to a large extent the same variables, even if these were not defined in exactly the same manner as for the rest of EPIC. A comprehensive re-coding scheme was developed for standardisation of the questionnaire variables from these study centres, to make the codes as close as possible to those of the core EPIC lifestyle questions.

\section{Antbropometric measurements}

In all EPIC centres, except France, the Oxford cohort and Norway, height, weight, and waist and hip circumference were measured on all subjects using similar protocols (in Umeå, only weight and height were measured). In addition, in Italy, Spain, Utrecht, Greece, Germany and Denmark, sitting height was measured. In France and Oxford, weight, height, waist and hip (and sitting height in France) were measured only for a restricted number of participants, but self-reported weight and height were obtained from all individuals. In Oxford, self-reported measurements also included waist and hip circumferences. In Norway only self-reported height and weight are available $^{34}$.

\section{Biological samples}

Biological samples including blood plasma, blood serum, white blood cells and erythrocytes were collected from 385747 of the 519978 EPIC study participants (Table 5). The procedure for storage of blood samples differed between the seven initial EPIC countries and the three Scandinavian countries that joined EPIC at a later stage.

In the former countries and in Naples (Italy), blood samples were aliquoted into 28 plastic straws containing $0.5 \mathrm{ml}$ each (12 plasma with sodium citrate, eight serum, four erythrocytes, four buffy coat for DNA). To ensure a high degree of standardisation, the same materials (syringes, straws, etc.) were purchased centrally and distributed to the centres. The samples were then split into two mirror halves of 14 aliquots each. One set was stored 
Table 4 Non-dietary information: the European Prospective Investigation into Cancer and Nutrition (EPIC) study

\begin{tabular}{|c|c|}
\hline Anthropometry & $\begin{array}{l}\text { All centres except Umeå (Sweden) and Troms } \varnothing \text { (Norway) have either self-reported (France and } \\
\text { part of the UK) or measured information on weight, height, hip circumference and waist circumference. } \\
\text { In Umeå (Sweden) and Troms (Norway) information is available on weight and height only. } \\
\text { Sitting height measurements were obtained in France, Italy, Spain, Utrecht, Greece, Germany and Denmark }\end{array}$ \\
\hline Reproductive history & $\begin{array}{l}\text { All core* centres (except Bilthoven, which has limited information) have detailed information } \\
\text { including, but not limited to, information on menopausal status, pregnancies, miscarriages, induced } \\
\text { abortion, infertility, and hormone use for both birth control and menopause. Of the associated } \\
\text { participants, the Danish and Norwegian centres have complete information, the centre in } \\
\text { Malmö (Sweden) has the majority of information, and the centre in Umeå (Sweden) has this } \\
\text { information on about half of the cohort, which is now increasing via follow-up }\end{array}$ \\
\hline Physical activity & $\begin{array}{l}\text { All core* centres have information on type of physical activity at work, physical exercise } \\
\text { to keep fit and vigorous physical activity, as well as time spent on specific activities including walking, cycling, } \\
\text { gardening, housework, and number of stairs climbed per day. Of the associated } \\
\text { participants, the Danish centres have complete information, the centre in Malmö (Sweden) has the } \\
\text { majority of the information, and the centre in Umeå (Sweden) is limited to information on } \\
\text { type of physical activity at work. The centres in Umeå and Tromsø have additional questions on } \\
\text { physical activity, which are not completely adapted to the core questionnaire }\end{array}$ \\
\hline Tobacco smoking & $\begin{array}{l}\text { All centres have information on smoking status (current, past, never), as well as information on } \\
\text { amount of cigarettes smoked. In addition, all centres (except those in The Netherlands and Norway) } \\
\text { have information on current and past cigar and pipe smoking }\end{array}$ \\
\hline Alcohol consumption & $\begin{array}{l}\text { The core* centres have information on past amount of wine, beer/cider, fortified wine and } \\
\text { spirit/liquor consumed. In addition, for Cambridge, Bilthoven and Greece, information on current } \\
\text { levels of consumption for each of these types of alcohol is available as non-dietary variable. } \\
\text { Of the associated participants, the Danish and Naples centres have complete information whereas } \\
\text { the centres in Malmö (Sweden) and Norway have information on current alcohol consumption only. } \\
\text { No information on past alcohol consumption is available in Umeå (Sweden). However, for all EPIC centres, } \\
\text { additional information on current alcohol consumption is available from the dietary questionnaires }\end{array}$ \\
\hline Occupational history & $\begin{array}{l}\text { The centres in Italy, Spain, Cambridge, Greece, Germany and Denmark have information } \\
\text { on occupational history. The Norwegian centre has information on current occupation }\end{array}$ \\
\hline Soci & All centres have information on highest school level achieved \\
\hline Previous illnesses & $\begin{array}{l}\text { All centres have information on heart disease and diabetes, while the majority (both core* and } \\
\text { associated participants) of centres have information on stroke, hypertension, hyperlipidaemia, gall } \\
\text { stones, polyps of the large bowl, hysterectomy, oopherectomy and breast surgery, as well as } \\
\text { information on age of onset of each of these events }\end{array}$ \\
\hline
\end{tabular}

* Core centres include centres in France, Italy (except Naples), Spain, UK, The Netherlands, Greece and Germany. The associated participants include centres in Sweden, Denmark, Norway and Naples (Italy).

locally, and one transported to IARC to be stored in liquid nitrogen (at $-196^{\circ} \mathrm{C}$ ) in a central biorepository.

In Norway the biological samples were collected in twenty $0.5 \mathrm{ml}$ plastic straws; for 9197 subjects, 12 of the 16 plasma and two of the four buffy coat samples were shipped to IARC for storage in the central repository. In Sweden and Denmark, blood samples were stored in tubes (not in plastic straws) and for practical reasons are stored only in local repositories (the central EPIC repository at IARC is not suitable for storing tubes). In Sweden, the samples are kept in freezers at $-70^{\circ} \mathrm{C}$, and in Denmark in nitrogen vapour $\left(-150^{\circ} \mathrm{C}\right)$.

The central biological bank located at IARC currently contains around 3.8 million straws with blood aliquots from 275861 EPIC participants. The straws of each participant are stored together successively inside a tube, goblet, canister and container. The canisters are arranged in colour-coded concentric circles located in each of 33 liquid nitrogen containers. Each straw is labelled with the participant's ID and colour-coded to indicate its contents; in addition, the tube, goblet and canister are colour-coded to aid in identifying the samples. Finally, a computer software program indicates the container, canister, goblet, and the location of the goblet and the canister within each container to track the stored biological samples of each participant.

\section{Follow-up for changes in lifestyle and bealth conditions}

After their initial enrolment, cohort members are contacted at regular intervals every 3-4 years to obtain information on various aspects of lifestyle that are known or strongly suspected of being related to cancer risk, and that may change over time. This includes tobacco smoking, alcohol drinking, physical activity, weight, menstruation, pregnancies, menopause, and other variables. In addition, a series of questions was added on whether the subjects had suffered from any major diseases. In most EPIC centres, the first follow-up is currently ongoing and in several it has been completed.

\section{Follow-up for cancer incidence and overall mortality}

Follow-up aimed at identifying cancer cases occurring among the EPIC cohort is based on population cancer registries in seven of the participating countries (Denmark, Italy, The Netherlands, Norway, Spain, Sweden and the UK) and on a combination of methods including health insurance records, cancer and pathology registries, and on active follow-up through study subjects and their next-ofkin in three countries (France, Germany and Greece). A working group created in 1996 (End-Point Committee) prepared a detailed protocol for the collection and 
Table 5 Biological samples: the European Prospective Investigation into Cancer and Nutrition (EPIC) study

\begin{tabular}{|c|c|c|c|c|c|c|c|c|c|c|c|}
\hline \multirow[b]{2}{*}{ Centre } & & \multirow[b]{2}{*}{$n$} & \multirow[b]{2}{*}{$\begin{array}{l}\text { Age range (years) } \\
\text { (1st-99th percentile) }\end{array}$} & \multirow[b]{2}{*}{$\begin{array}{l}\text { Female } \\
(\%)\end{array}$} & \multirow[b]{2}{*}{$\begin{array}{l}\text { Achievement } \\
\left.\text { rate* }^{*} \%\right)\end{array}$} & \multicolumn{4}{|c|}{$\begin{array}{c}\text { Samples collected } \dagger \\
\text { (number of } 0.5 \mathrm{ml} \text { straws desired) }\end{array}$} & \multicolumn{2}{|c|}{$\begin{array}{l}\text { Storage } \\
\text { location }\end{array}$} \\
\hline & & & & & & Plasma & Serum & $\begin{array}{l}\text { White } \\
\text { blood } \\
\text { cells }\end{array}$ & Erythrocytes & IARC & Local \\
\hline \multicolumn{12}{|c|}{ Core EPIC cohorts } \\
\hline Greece & Nation-wide & 28500 & $29-76$ & 58.2 & 99.8 & 12 & 8 & 4 & 4 & Yes & Yes \\
\hline \multirow[t]{5}{*}{ Spain } & Granada & 6892 & $35-66$ & 77.0 & 87.5 & 12 & 8 & 4 & 4 & Yes & Yes \\
\hline & Murcia & 8146 & $35-65$ & 68.7 & 95.7 & 12 & 8 & 4 & 4 & Yes & Yes \\
\hline & Navarra & 7799 & $36-64$ & 51.5 & 96.5 & 12 & 8 & 4 & 4 & Yes & Yes \\
\hline & San Sebastian & 8325 & $36-65$ & 50.6 & 98.9 & 12 & 8 & 4 & 4 & Yes & Yes \\
\hline & Asturias & 8417 & $35-65$ & 64.0 & 98.5 & 12 & 8 & 4 & 4 & Yes & Yes \\
\hline \multirow[t]{4}{*}{ Italy } & Ragusa & 6396 & $35-65$ & 52.3 & 99.9 & 12 & 8 & 4 & 4 & Yes & Yes \\
\hline & Florence & 13597 & $35-65$ & 74.2 & 100.0 & 12 & 8 & 4 & 4 & Yes & Yes \\
\hline & Turin & 10604 & $35-64$ & 43.0 & 100.0 & 12 & 8 & 4 & 4 & Yes & Yes \\
\hline & Varese & 12073 & $36-72$ & 78.9 & 99.9 & 12 & 8 & 4 & 4 & Yes & Yes \\
\hline France & & 20725 & $43-68$ & 100.0 & $31.0 \ddagger$ & 12 & 8 & 4 & 4 & Yes & Yes \\
\hline \multirow[t]{2}{*}{ Germany } & Heidelberg & 24235 & $36-64$ & 52.6 & 94.9 & 12 & 8 & 4 & 4 & Yes & Yes \\
\hline & Potsdam & 26444 & $35-66$ & 59.8 & 95.9 & 12 & 8 & 4 & 4 & Yes & Yes \\
\hline \multirow[t]{2}{*}{ Netherlands } & Bilthoven & 19388 & $21-64$ & 54.0 & $93.1 \S$ & 12 & 8 & 4 & 4 & Yes & Yes \\
\hline & Utrecht & 16930 & $49-69$ & 100.0 & 96.9 & 12 & 8 & 4 & 4 & Yes & Yes \\
\hline \multirow{2}{*}{ United Kingdom } & Cambridge & 24035 & $41-76$ & 54.3 & $93.8 \eta$ & 12 & 8 & 4 & 4 & Yes & Yes \\
\hline & Oxford & 19103 & $23-73$ & 76.7 & $96.1 \|$ & 12 & 8 & 4 & 4 & Yes & Yes \\
\hline \multicolumn{12}{|c|}{ Associated EPIC cohorts } \\
\hline Italy & Naples & 5055 & $34-68$ & 100.0 & 99.9 & 12 & 8 & 4 & 4 & No & Yes \\
\hline \multirow[t]{2}{*}{ Denmark } & Aarhus & 17094 & $50-65$ & 50.8 & 99.7 & $\mathrm{~T}^{\mathrm{b}}$ & $\mathrm{T}^{\mathrm{b}}$ & $T^{\mathrm{b}}$ & $\mathrm{T}^{\mathrm{b}}$ & No & Yes \\
\hline & Copenhagen & 39037 & $50-65$ & 52.7 & 97.8 & $\mathrm{~T}^{\mathrm{b}}$ & $\mathrm{T}^{\mathrm{b}}$ & $\mathrm{T}^{\mathrm{b}}$ & $\mathrm{T}^{\mathrm{b}}$ & No & Yes \\
\hline \multirow[t]{2}{*}{ Sweden } & Malmö & 28023 & $46-73$ & 60.6 & 99.7 & $\mathrm{~T}^{\mathrm{a}}$ & $\mathrm{T}^{\mathrm{a}}$ & $\mathrm{T}^{\mathrm{a}}$ & $\mathrm{T}^{\mathrm{a}}$ & No & Yes \\
\hline & Umeå & 25732 & $30-61$ & 51.7 & 100.0 & $\mathrm{~T}^{\mathrm{a}}$ & $\mathrm{T}^{\mathrm{a}}$ & $\mathrm{T}^{\mathrm{a}}$ & $\mathrm{T}^{\mathrm{a}}$ & No & Yes \\
\hline Norway & Troms $\varnothing$ & 9197 & $40-55$ & 100.0 & $\sim 60.0^{\star \star}$ & 16 & NC & 4 & NC & Yes & Yes \\
\hline
\end{tabular}

$\mathrm{T}^{\mathrm{a}}$ - stored in $2 \mathrm{ml}$ tubes at $-80^{\circ} \mathrm{C} ; \mathrm{T}^{\mathrm{b}}$ - stored in $1 \mathrm{ml}$ tubes in nitrogen vapour at a temperature between $-150^{\circ} \mathrm{C}$ and $-160^{\circ} \mathrm{C} ; \mathrm{NC}-$ not collected.

* In all centres, except those in France, the UK, Bilthoven (Netherlands) and Norway, all EPIC participants were invited to donate blood (Table 2 contains the denominator used to calculate the achievement rate, which represents the percentage of participants with partial or complete stored biological samples out of those asked to donate blood).

$\dagger$ In the core centres, biological samples are distributed equally between IARC and local storage, and are stored in straws at $-196^{\circ} \mathrm{C}$.

$\ddagger$ In France, 66858 EPIC participants living near a metropolitan area were asked to give blood.

$\S$ In Bilthoven, 13451 EPIC participants recruited from Amsterdam or Doetinchem after 11 May 1993, and 7364 EPIC participants recruited from Maastricht after 2 June 1993, were asked to donate blood.

I In Cambridge (UK), 25633 EPIC participants who attended a study exam were asked to give blood.

$\|$ In Oxford (UK), enrolment of the participants recruited by general practitioners from the local counties was based on a willingness to donate blood and the achievement rate is $96.1 \%$; among the 'health-conscious' sub-cohort, $24.4 \%$ donated blood.

${ }^{\star *}$ In Norway, collection of biological samples is currently underway and will continue until samples have been collected from 12000 participants.

standardisation of clinical and pathological data on each cancer site: Guidelines for Collection of End-point Data in the EPIC Study (IARC, 1998). In parallel, data on total and cause-specific mortality are collected at the EPIC study centres through mortality registries or active follow-up and death-record collection.

\section{Storage, management and quality control of the EPIC database}

The EPIC data are housed centrally at IARC in the EPIC ORACLE database. For practical reasons, 14 centres in the 10 participating countries act as co-ordinating centres that interact with IARC for centralisation of the EPIC data (in particular, all Spanish and Italian data are centralised in Barcelona and Milan, respectively). The database comprises individual EPIC data, as well as the computer software (ORACLE) and the programs that store, track and manage the database.

The EPIC core information concerning non-dietary lifestyle variables and anthropometry is stored in the EPIC
ORACLE database, using the centre-specific variable names and formats as well as variable names and formats standardised across EPIC. Centre-specific data were loaded into the ORACLE system, and transformed into the standard EPIC variables on which logical and substantive quality control checks were then run. Figure 1 summarises the process.

For dietary data, a common format and classification system was proposed to enable centralised data management and a series of pooled analyses. The food items reported in each EPIC dietary questionnaire were classified in their respective food groups using the same system as that used to classify the food items reported in the EPIC-SOFT 24-hour dietary recalls (the so-called EPICSOFT food classification system $)^{35}$. However, other classification criteria may be considered on an individual basis depending on the purposes of specific analyses. In addition, the frequency of consumption of each item, the number of portions consumed on each occasion and the (standard) portion sizes were also stored in the central 


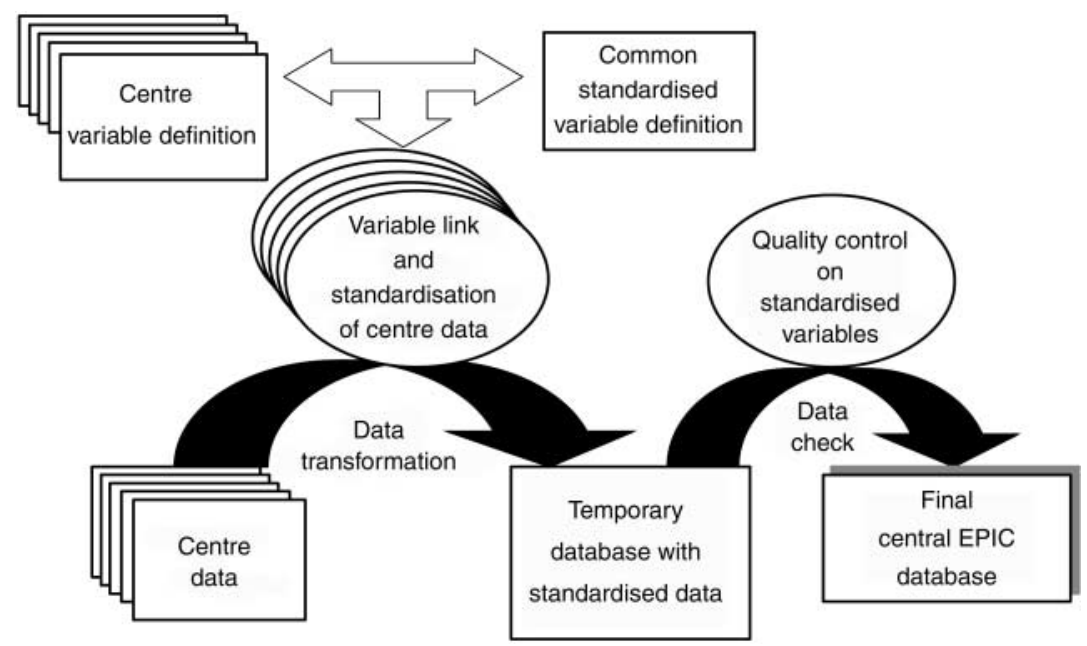

Fig. 1 Flow chart of lifestyle and personal data: the European Prospective Investigation into Cancer and Nutrition study

ORACLE database; hence, the total quantity of each food was calculated from this information as grams consumed per day. For the 24-hour dietary recalls, used as common reference calibration measurements, the same standardised software (i.e. EPIC-SOFT) methodology was used in all centres to collect and subsequently store, retrieve and export these data. The same format file was therefore used to load and store the 24-hour dietary recall data in the central EPIC database.

The storage, management and interrelationships between the various components of the EPIC dietary data are shown schematically in Fig. 2.

Personal identifying information, as available at local centres, is not transferred to the IARC co-ordinating centre. Informed consent was provided by each participant, and projects using the EPIC resource need to be cleared by both the IARC and local ethical review committees.

\section{Concluding remarks}

Approximately 10 years after its inception, the EPIC study baseline information and biological samples have been collected, centralised and, when applicable, standardised.

As a large prospective cohort with stored biological samples, EPIC is now starting to generate specific studies investigating cancer aetiology in relation to diet and lifestyle factors, and this will continue over the next 10 years and beyond. When biological samples are involved, these studies mostly use the nested case-control approach. In addition, information on vital status and cause of death can be used to address endpoints other than cancer, in particular cardiovascular diseases, as well as survival after cancer diagnosis.

The very magnitude of the individual and total cohorts, the related lengthy period of subject recruitment and the variety of local facilities have made it impossible to standardise all of the procedures strictly, as would be possible for smaller studies. However, considerable effort has been put into ensuring maximum comparability within and between cohorts, in particular where dietary information is concerned, by means of the large calibration sub-sample. The storage of biological samples

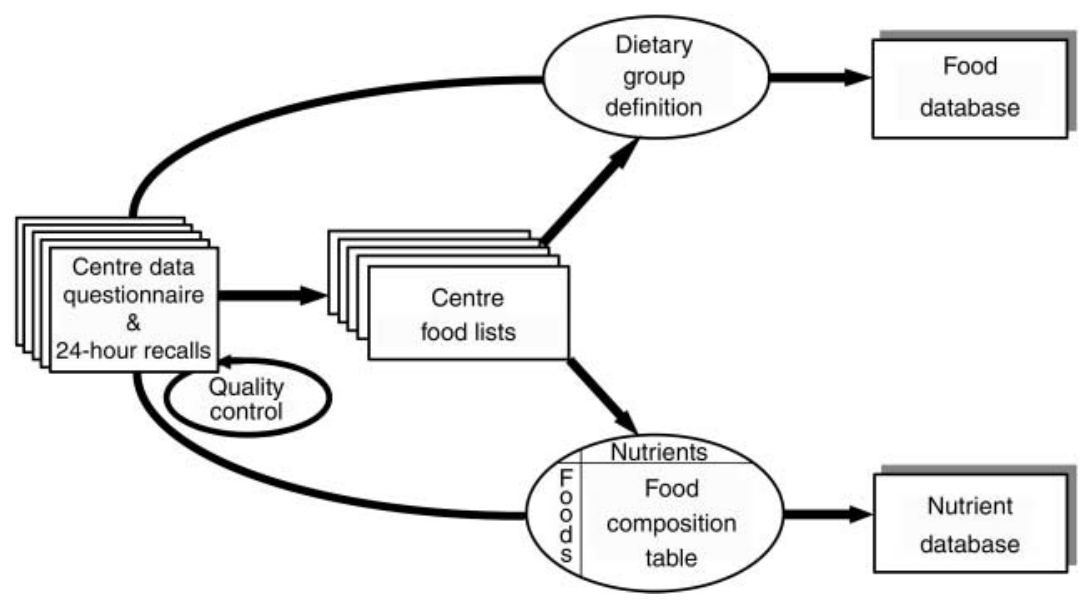

Fig. 2 Flow chart of dietary data: the European Prospective Investigation into Cancer and Nutrition study 
in multiple aliquots in liquid nitrogen represents the best available technology for maintaining long-term stability.

A multi-centre cohort the size of EPIC offers the substantial advantage of enabling informative studies on common cancers (as well as other common causes of deaths) not only overall but also in specific subsets of the total population, within which aetiological factors may differ. Also, sufficient numbers will accrue to enable meaningful investigation of rarer cancers. Finally, the variations in disease rates, diet and lifestyles across the populations included in EPIC raise interesting methodological issues on the one hand and, on the other, the opportunity to capitalise simultaneously on the withinand between-centre variability to increase the capacity of the study to clarify the complex role of nutrition in the causation and prevention of cancer.

\section{Acknowledgements}

The work described in this paper was carried out with financial support of the 'Europe Against Cancer' Programme of the European Commision (SANCO); Ligue contre le Cancer (France); Société 3M (France); Mutuelle Générale de l'Education Nationale; Institut National de la Santé et de la Recherche Médicale (INSERM); Institute Gustave Roussy; German Cancer Aid; German Cancer Research Centre; German Federal Ministry of Education and Research; Danish Cancer Society; Health Research Fund (FIS) of the Spanish Ministry of Health; the Spanish Regional Governments of Andalucia, Asturias, Basque Country, Murcia and Navarra; Cancer Research UK; Medical Research Council, UK; Stroke Association, UK; British Heart Foundation; Department of Health, UK; Food Standards Agency, UK; Wellcome Trust, UK; Greek Ministry of Health; Greek Ministry of Education; Italian Association for Research on Cancer; Italian National Research Council; Dutch Ministry of Public Health, Welfare and Sports; Dutch Prevention Funds; LK Research Funds; Dutch ZON (Zorg Onderzoek Nederland); World Cancer Research Fund; Swedish Cancer Society; Swedish Scientific Council; Regional Government of Skane, Sweden; Norwegian Cancer Society; Norwegian Research Council. Partial support for the publication of this supplement was provided by the Centre de Recherche et d'Information Nutritionnelles (CERIN).

In addition, we wish to thank all study participants for their co-operation and all interviewers who participated in the fieldwork studies in each EPIC centre.

\section{References}

1 Tannenbaum A. Initiation and growth of tumors; introduction: effects of underfeeding. Am. J. Cancer 1940; 39: 335-50.

2 Doll R, Payne P, Waterhouse J. Cancer Incidence in Five Continents: A Technical Report. Berlin: Springer, 1966.
3 Doll R, Payne P, Waterhouse J. Cancer Incidence in Five Continents. Berlin: Springer, 1970.

4 Armstrong B, Doll R. Environmental factors and cancer incidence and mortality in different countries, with special reference to dietary practices. Int. J. Cancer 1975; 15: 617-31.

5 World Cancer Research Fund/American Institute of Cancer Research (WCRF/AICR). Food, Nutrition and the Prevention of Cancer: A Global Perspective. Washington, DC: WCRF/AICR, 1997.

6 Riboli E. Nutrition and cancer: background and rationale of the European Prospective Investigation into Cancer and Nutrition (EPIC). Ann. Oncol. 1992; 3: 783-91.

7 Riboli E. The European Prospective Investigation into Cancer and Nutrition: perspectives for cancer prevention. Nestle Nutr. Workshop Ser. Clin. Perform. Programme 2000; 4: $117-30$.

8 Riboli E. The European Prospective Investigation into Cancer and Nutrition (EPIC): plans and progress. J. Nutr. 2001; 131: 170S-5S

9 Riboli E, Kaaks R. The EPIC Project: rationale and study design. European Prospective Investigation into Cancer and Nutrition. Int. J. Epidemiol. 1997; 26(Suppl. 1): S6-14.

10 Riboli E, Kaaks R. Invited commentary: the challenge of multi-center cohort studies in the search for diet and cancer links. Am.J. Epidemiol. 2000; 151: 371-4.

11 Berglund G, Elmstahl S, Janzon L, Larsson SA. The Malmö Diet and Cancer Study. Design and feasibility. J. Intern. Med. 1993; 233: 45-51.

12 Clavel-Chapelon F, van Liere MJ, Giubout C, Niravong MY, Goulard H, Le Corre C, et al. E3N, a French cohort study on cancer risk factors. E3N Group. Etude Epidémiologique auprès de femmes de l'Education Nationale. Eur. J. Cancer Prev. 1997; 6: 473-8.

13 Hjartåker A, Lund E. Relationship between dietary habits, age, lifestyle, and socio-economic status among adult Norwegian women. The Norwegian Women and Cancer Study. Eur. J. Clin. Nutr. 1998; 52: 565-72.

14 Boeing $\mathrm{H}$, Wahrendorf J, Becker N. EPIC-Germany - a source for studies into diet and risk of chronic diseases. Ann. Nutr. Metab. 1999; 43: 195-204.

15 Boeing $\mathrm{H}$, Korfmann A, Bergmann MM. Recruitment procedures of EPIC-Germany. European Investigation into Cancer and Nutrition. Ann. Nutr. Metab. 1999; 43: 205-15.

16 Day N, Oakes S, Luben R, Khaw KT, Bingham S, Welch A, et al. EPIC-Norfolk: study design and characteristics of the cohort. European Prospective Investigation of Cancer. $\mathrm{Br}$. J. Cancer. 1999; 80(Suppl. 1): 95-103.

17 Keinan-Boker L, van Noord PAH, van der Schouw YT, Koot NVCM, Bueno-de-Mesquita HB, Riboli E, et al. ProspectEPIC Utrecht: study design and characteristics of the cohort population. Eur. J. Epidemiol. 2002; in press.

18 Schulze MD, Kroke A, Saracci R, Boeing H. The effect of measurement procedure differences on the comparability of blood pressure estimates in multi-centre studies. Blood Press. Monit. 2000; 7: 95-104.

19 Overvad K, Tjønneland A, Haraldsdóttir J, Bang S, Ewertz M, Møller-Jensen O. Development of a semi-quantitative food frequency questionnaire to assess food, energy and nutrient intake in Denmark. Int. J. Epidemiol. 1991; 20: 906-12.

20 Bingham SA, Gill C, Welch A, Day K, Cassidy A, Khaw KT, et al. Comparison of dietary assessment methods in nutritional epidemiology: weighted records v. $24 \mathrm{~h}$ recalls, food-frequency questionnaires and estimated-diet records. Br. J. Nutr. 1994; 72: 619-43.

21 Margetts BM, Pietinen P, Riboli E, eds. EPIC: European Prospective Investigation into Cancer and Nutrition: validity studies on dietary assessment methods [special issue]. Int. J. Epidemiol. 1997; 26(Suppl. 1): S1-189.

22 Riboli E, Elmståhl S, Saracci R, Gullberg B, Lindgärde F. The 
Malmö Food Study: validity of two dietary assessment methods for measuring nutrient intakes. Int. J. Epidemiol. 1997; 26: S161-71.

23 Kroke A, Klipstein-Grobusch K, Voss S, Moseneder J, Thielecke F, Noack R, et al. Validation of a self-administered food-frequency questionnaire administered in the European Prospective Investigation into Cancer and Nutrition (EPIC) Study: comparison of energy, protein, and macronutrient intakes estimated with the doubly labeled water, urinary nitrogen, and repeated 24-h dietary recall methods. Am J. Clin. Nutr. 1999; 70: 439-47.

24 Slimani N, Deharveng G, Charrondière RU, van Kappel AL, Ocké MC, Welch A, et al. Structure of the standardized computerized 24-h diet recall interview used as reference method in the 22 centers participating in the EPIC project European Prospective Investigation into Cancer and Nutrition. Comput. Meth. Programs Biomed. 1999; 58: 251-66.

25 Slimani N, Ferrari P, Ocké M, Welch A, Boeing H, Liere M, et al. Standardization of the 24-hour diet recall calibration method used in the European Prospective Investigation into Cancer and Nutrition (EPIC): general concepts and preliminary results. Eur. J. Clin. Nutr. 2000; 54: 900-17.

26 Slimani N, Kaaks R, Ferrari P, Casagrande C, Clavel-Chapelon F, Lotze G, et al. European Prospective Investigation into Cancer and Nutrition (EPIC) calibration study: rationale, design and population characteristics. Public Health Nutr. 2002; 5(6B): 1125-45.

27 Kaaks R, Riboli E. Validation and calibration of dietary intake measurements in the EPIC project: methodological considerations. European Prospective Investigation into Cancer and Nutrition. Int. J. Epidemiol. 1997; 26(Suppl. 1): S15-25.

28 Kaaks R, Plummer M, Riboli E, Esteve J, van Staveren W. Adjustment for bias due to errors in exposure assessments in multicenter cohort studies on diet and cancer: a calibration approach. Am. J. Clin. Nutr. 1994; 59: 245S-50S.

29 Kaaks R, Riboli E, Esteve J, van Kappel AL, van Staveren WA Estimating the accuracy of dietary questionnaire assessments: validation in terms of structural equation models. Stat. Med. 1994; 13: 127-42.

30 Kaaks R, Riboli E, van Staveren W. Sample size requirements for calibration studies of dietary intake measurements in prospective cohort investigations. Am. J. Epidemiol. 1995; 142: $557-65$.

31 Kaaks R, Riboli E, van Staveren W. Calibration of dietary intake measurements in prospective cohort studies. Am. J. Epidemiol. 1995; 142: 548-56.

32 Slimani N, Charrondière UR, van Staveren W, Riboli E. Standardization of food composition databases for the European Prospective Investigation into Cancer and Nutrition (EPIC): general theoretical concept. J. Food Comp. Anal. 2000; 13: 567-84.

33 Charrondière UR, Vignat J, Møller A, Ireland J, Becker W, Church S, et al. The European Nutrient Database (ENDB) for nutritional epidemiology. J. Food Comp. Anal. 2002; 15(4): $435-51$.

34 Haftenberger M, Lahmann PH, Panico S, González CA, Seidell JC, Boeing $\mathrm{H}$, et al. Overweight, obesity and body fat distribution in 50- to 64-year-old participants in the European Prospective Investigation into Cancer and Nutrition (EPIC). Public Health Nutr. 2002; 5(6B): 1147-62.

35 Ireland J, van Erp-Baart AMJ, Charrondière UR, Møller A, Smithers G, Trichopoulou A, for the EFCOSUM Group. Selection of a food classification system and a food composition database for future food consumption surveys. Eur. J. Clin. Nutr. 2002; 56(Suppl. 2): S33-45. 